\title{
Using VoiceThread to Aid Teaching Speaking Skills
}

Hung Thi Hong Nguyen

Thai Binh Gifted High School, Thai Binh Province

\begin{abstract}
Speaking skills are essential for English as foreign language students in everyday and academic tasks. However, it is an arduous and challenging task for teachers to teach speaking skills. This session will discuss one of the effective approaches to aid teachers in their teaching by using VoiceThread.
\end{abstract}

\section{Session Description}

VoiceThread is powerful 2.0 web tool that enables users to create recordings and leave comments (Langer de Ramirez, 2009), in many different ways, such as voice, texts, audio files, or video. A multitude of cloud-based conversations can be generated with VoiceThreads by inviting other people to comment in the same ways. It can improve users' sense of connection by creating an online communication environment. Also, this asynchronous tool is extremely flexible - users can access it at different times, and each time they do, their additions will be saved (Haverkate-Ens 2014) making this tool highly applicable in teaching and learning speaking and listening skills. This session will instruct participants to create a VoiceThread account and report on the way EFL teachers use VoiceThread to teach speaking skills by creating an online class setting in which teachers will be the administrator managing students’ accounts. The presenter shows how various class assignments can be created and how students can participate in an asynchronous way. The presenter also gives two sample speaking activities in which participants will act as students to do the tasks. Finally, the presenter will generate a discussion among participants about whether these sample activities work in their own settings and explain the reasons for it and explore ways to adapt these activities other classroom settings. Participants will also be encouraged to suggest other ways teachers can use VoiceThread to promote speaking activities. This presentation will be useful to EFL teachers who would like to apply technology to teaching and turn the traditional speaking class into in a fun, creative, friendly, and efficient one. 


\section{References}

Haverkate-Ens, D. (2014). VoiceThread: A technology tool worth your time. Issues in Language Instruction: Special Issue.

Langer de Ramirez, L. (2009). Empower English Language Learners with Tools From the Web. Thousand Oaks, CA: Corwin Press. 